\title{
The Association of Extracranial and Intracranial Vascular Malformations in Children
}

\author{
Ignacio Pascual-Castroviejo
}

\begin{abstract}
This review is an attempt to relate the types of angiomas and other cutaneous vascular lesions appearing in the face with abnormalities in the formation of cerebral vessels including arteries at their origin, veins and venous sinuses, and with other less constant alterations that affect other organs, particularly the heart and cerebellum. After angiographic study of a series of patients exhibiting diverse types of vascular nevi (capillary and cavernous hemangiomas, nevus flammeus, and lymphangiomas). a correlation was established for each type of dermal nevus with a corresponding group of intracranial vascular anomalies. An explanation of these malformations based on the embryological development of the principal cerebral vessels during the 7 th and 8 th weeks of gestation is offered. Involvement of the facial and scalp dermatome innervated by the first sensory trigeminal branch correlates most consistently with the presence of abnormal cerebral vessels. The capillary hemangioma occurs preferentially in girls and frequently is associated with developmental anomalies of major cerebral arteries characterised by the absence of some adult vessels and the persistence of others that should have disappeared during embryogenesis such as the fetal trigeminal artery. The complete angiographic exploration of the cerebral vessels from their origin in the aortic arch to the phase of intracranial venous evacuation may reveal unexpected important findings, and is recommended for children with major facial vascular nevi, even if they are neurologically asymptomatic.
\end{abstract}

RÉSUMÉ: L'association de malformations vasculaires extracrâniennes et intracrâniennes chez l'enfant Cette revue essaye d'établir un rapport entre les types d'angiomes et d'autres atteintes cutanées vasculaires de la figure, et des anomalies en développement de vaisseaux cérébraux comprenant les artères à leurs origines, les veines et les sinus veineux. Également on discute d'autres anomalies moins constamment trouvées qui s'agissent d'autres organes, plus particulièrement le coeur et le cervelet. Après l'étude angiographique d'une serie de patients qui montrèrent des types divers de naevus (hémangiomes capillaires et caverneux, et lymphangiomes), une corrélation fut établie entre chaque type de naevus dermal et un groupe correspondant d'anomalies intracrâniennes vasculaires. On propose une explication de ces malformations à propos du développement embryonnaire des vaisseaux cérébraux principaux pendant la 7 ième et 8 ième semaine de gestation. L'atteinte du dermatome facial et épricrânien innervé par le premier rameau trigéminé sensoriel se trouve en corrélation avec la présence des vaisseaux cérébraux anormaux. L'hémangiome capillaire montre une préférence à des filles et il est souvant associé à des anomalies en développement des artères cérébrales principales, caracterisées par l'absence de certaines vaisseaux de l'adulte et par la persistence d'autres qui auraient dû disparu durant l'embryogenèse, par example l'artère trigéminée foetal. L'examen angiographique complèt des vaisseaux cérébraux, de son origin dans la crosse de l'aorte à la phase d'évacuation intracrânienne veineuse peut révéler des données importantes imprévues. On suggère un tel examen pour des enfants atteints de naevus faciaux de grande dimension, même s'ils ne soient pas symptomatiques au point de vue neurologique.

Can. J. Neurol. Sci. 1985: 12:139-148

The medical literature refers with some frequency to the clinical features, particularly the morphological characteristics, of the various types of port wine stains and other vascular lesions that appear externally on the face and/or scalp. Entire monographs ${ }^{1}$ and histologic descriptions ${ }^{2}$ have contributed to the recognition of the pathology and natural evolution of each of these external vascular malformations.

It is curious to note, nevertheless, the sparse amount of accumulated experience and scant interest that the possible coexistence of anomalies of the intracranial vessels with external vascular nevi has generated. The notable exception is the SturgeWeber syndrome, in which not only are the angiographic findings well documented, but the biological variations also are well described.
We routinely carry out carotid angiography in children with facial cutaneous vascular lesions. These studies usually are bilateral and in many cases we also examine the vertebrobasilar system, permitting us to compile a large series in which all major anomalies are represented. Our personal experience, here presented, constitutes the basis of the conclusions and commentary, and includes some of the neuroradiological findings we have previously reported. ${ }^{3.4}$ Given the dysembryonic character of the intracranial anomalies that accompany external vascular alterations. I have attempted to reconcile these ontogenetic malformations with classical embryological studies espousing the origin and development of the cerebral vessels. ${ }^{5-9}$

Some vascular processes of the skin have specifically been excluded because, in our experience, they are not associated 
with intracranial alterations of blood vessels. An example is the spider nevus or hereditary hemorrhagic telangiectasia (RenduOsler-Weber syndrome). Also excluded are diseases consisting of progressive occlusive arteriopathy involving blood vessels of medium size but in which malformations of intracranial vessels also have not been demonstrated, as in cutis marmorata (also known as livido reticularis or Sneddon syndrome), ${ }^{10}$ and the Divry-van Bogaert syndrome of diffuse leptomeningeal capillary venous angiomatosis in which changes in the cutaneous capillaries are mild and nonspecific." We also exclude the
Klippel-Trenaunay syndrome because its intrinsic nature in most cases is the Sturge-Weber syndrome or a related vasculopathy. The angiokeratomas, the Maffucci syndrome, papular angioplasia, unilateral nevoid telangiectasia, and ataxiatelangiectasia (Louis-Barr syndrome) are excluded because they do not constitute vascular malformations seen in the face or are not evident at birth, and moreover because they are not associated with intracranial vascular malformations.

The most interesting and representative cases of our series are summarized in Table I.

Table 1: Representative cases of 38 children with facial hemangiomas studied arteriographically.

\begin{tabular}{|c|c|c|c|c|c|c|c|}
\hline Case & Age/Sex & $\begin{array}{l}\text { Type of } \\
\text { Angioma } \\
\end{array}$ & $\begin{array}{l}\text { Cutaneous } \\
\text { Location } \\
\end{array}$ & Vascular Malformation & Other CNS Malformations & Cardiac Anomalies & $\begin{array}{l}\text { Mental } \\
\text { Development }\end{array}$ \\
\hline 1 & $20 \mathrm{mo} \mathrm{F}$ & capillary & right scalp & $\begin{array}{l}\text { persisitent right } \\
\text { trigeminal artery }\end{array}$ & none & none & retarded \\
\hline 2 & 5 yr F & capillary & $\begin{array}{l}\text { left face in } V_{1} \\
\text { distribution: } \\
\text { external } \\
\text { genitalia }\end{array}$ & $\begin{array}{l}\text { segmental intervertebral } \\
\text { anastomoses }\end{array}$ & none & $\begin{array}{l}\text { patent ductus arteriosus; } \\
\text { aortic atresia }\end{array}$ & normal \\
\hline 4 & $7 \mathrm{mo} \mathrm{F}$ & capillary & $\begin{array}{l}\text { left face in } \\
V_{1}, v_{2}, V_{3} \\
\text { distribution: } \\
\text { dysplastic left } \\
\text { ear }\end{array}$ & $\begin{array}{l}\text { absence of left carotid } \\
\text { and left vertebral arteries: } \\
\text { supratentorial vasculari- } \\
\text { zation via right carotid } \\
\text { artery with angiomatosis } \\
\text { and pathologic distribution }\end{array}$ & Dandy-Walker malformation & none & retarded \\
\hline 5 & 3 yr F & capillary & $\begin{array}{l}\text { left face in } \\
V_{1}, V_{2} \cdot v_{3} \\
\text { distribution }\end{array}$ & $\begin{array}{l}\text { arterial angiomatous } \\
\text { malformation in region of } \\
\text { left carotid siphon; hypo- } \\
\text { plasia of left PICA }\end{array}$ & global cerebellar hypoplasia & none & $\begin{array}{l}\text { mildly } \\
\text { retarded }\end{array}$ \\
\hline 6 & $3 \mathrm{mo} \mathrm{F}$ & capillary & $\begin{array}{l}\text { left face in } \\
v_{1}, V_{2}, v_{3} \\
\text { distribution }\end{array}$ & $\begin{array}{l}\text { angiomatous malformation } \\
\text { in region of left carotid } \\
\text { siphon and to lesser } \\
\text { extent of left anterior } \\
\text { cerebral artery }\end{array}$ & none & none & $\begin{array}{l}\text { mildly } \\
\text { retarded }\end{array}$ \\
\hline 7 & 2 yr F & capillary & $\begin{array}{l}\text { bilateral face in } \\
V_{1}, V_{2}, V_{3} \\
\text { distribution }\end{array}$ & $\begin{array}{l}\text { angiomatous malformation } \\
\text { of bilateral internal carotid } \\
\text { arteries including siphons }\end{array}$ & none & none & $\begin{array}{l}\text { mildly } \\
\text { retarded }\end{array}$ \\
\hline
\end{tabular}

Figure I - Case 3. (A) 6-month-old girl with capillary hemangioma in the left facial zone immervated by the first and second sensory branches of the trigeminal nerve and in the righ facial zone innervated by the third trigeminal branch. $(B$ and $C)$ Lateral projection of right carotid and vertebral arteriogram from injection of righ brachial artery. The carotid is tortuous, but shows a normal configuration at the carotid siphon. The basilar artery bifurcates upon reaching the mid-upper portion of the clivus (arrow), continuing its trajectory on one side to give origin to the superior anterior cerebellar arteries and posterior cerebral arleries (arrow' with single hash). It also gives rise to a thick and tortuous branch directed forward and superiorly (double arrow's with hashes) to form hemispheric ramifications, giving the impression that this last branch might be a persistent trigeminal artery which fills via the vertebral artery. ( $D$ and E) The anteroposterior projection shows a normal distribution from the cerebral arteries arising from the right internal carotid and the filling of the anterior cerebral arteries from the right carotid. The basilar artery is situated far laterally to the left and bifurcates (arrow) to gite contimuity of the basilar on one side (arrow with hash) and, on the other. to fill the left trigeminal through which all left carotid branches except the anterior cerebral artery are supplied. (F) Angiography of the aortic arch by cardiac catheterisation shows the absence of common carotid arteries and of the left vertebral. with a normal appearance of the subclavian artery and brachiocephalic trunk on the right side. $(G)$ Computed tomography of the brain in which the image of a retrocerebellar arachnoidal cyst is seen, associated with hypoplasia of the left cerebellar hemisphere. (See page 14I) 

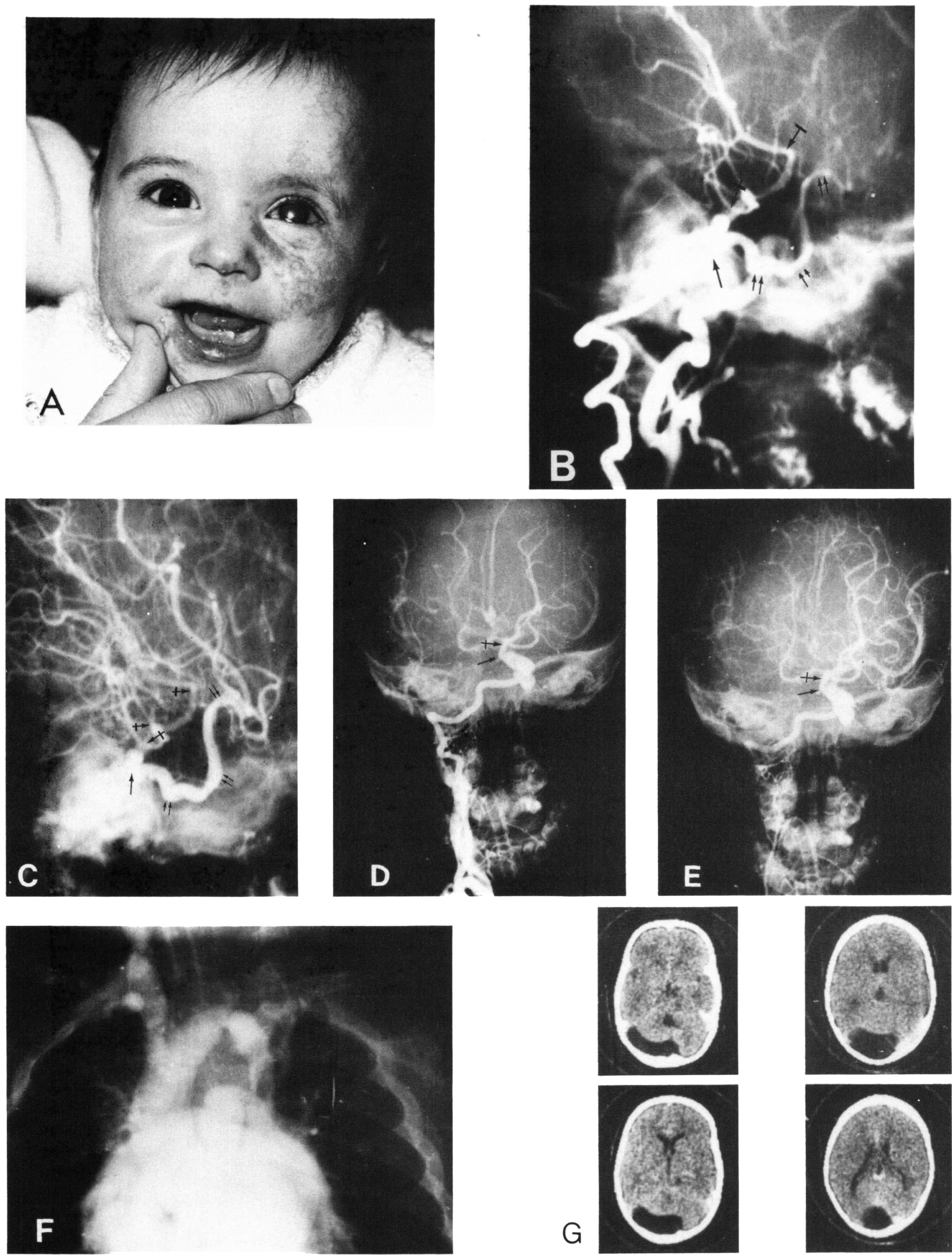

G

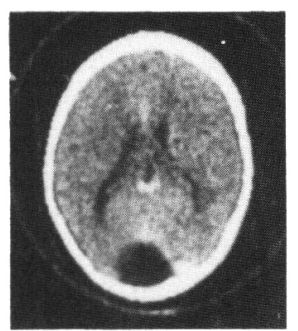


Types of external cutaneous lesions most commonly associated with intracranial vasculopathies

Capillary Hemangioma - This 'strawberry mark' may appear in isolated form (solitary hemangioma) or may form diverse lobulations of variable size and bright colour. It extends through the subcutaneous tissues of the head, face, neck, and other parts of the body, particularly in the genital zone. It is not rare to find it in the facial sensory dermatomes of one, two, or all three trigeminal branches, but especially the first and second. The capillary hemangioma generally appears between the third and fifth weeks of life, increasing in size over several months, and often beginning to regress in the second year. Approximately 70 percent of cases gradually but completely resolve spontaneously over several years; only 6 or 7 percent require plastic surgery. In some cases external ears, lips, nose, eyebrows, and eyelids are disfigured. One of our cases presented with leukokeratosis a few months after the vascular abnormality appeared in the face and the eye (Fig. 1). In another an ear involved by the hemangioma remained in a phase of development corresponding to the embryonic stage of $13 \mathrm{~mm}$ (6.5 weeks gestation) and was accompanied by very serious vascular malformations (Fig. 2).

These hemangiomas exhibit proliferation of their endothelial cells during the period of growth in the first few months of life. The lumen of the capillaries is narrow, widening during the phase of maturation. In the involutional phase hyaline deposits may be observed in the walls of capillaries that progressively narrow and result in occlusion of the lumen. In the final phase capillaries are replaced by edematous collagenous tissue.

The capillary angioma, in our experience, occurs preferentially in girls, all 7 of our cases being female, and is frequently associated with both intracranial and extracranial vascular anomalies, with congenital heart disease, and with defective neural structures of the posterior fossa. ${ }^{4}$

Cavernous Hemangioma - This consists of one or more commonly several poorly delineated dermal and subcutaneous nodules capable of achieving great volume and prominence, although soft and easily compressed. They may appear at any age, but the most voluminous ones are already present at birth. Some are gigantic in size. localised on one or both sides of the head and distorting the face giving a monsterous appearance (Fig. 3). The usual localisation of an isolated nodule is in the frontal, intraorbital, or periorbital zone. An association of cavernous hemangioma with capillary hemangioma has been documented several times. and an association also is known with nevus flammeus. The usual colour is bluish red, changing to dark blue and becoming more voluminous with crying.

From the histologic point of view, the cavernous hemangioma in the deep dermis and subcutaneous tissue exhibits wide, irregular spaces occupied by blood and fibrinous material. The fibrous walls of the large vascular spaces are variable in thickness. the separation between the distinct spaces by a lining of fine endothelial cells. On occasion, endothelial cell proliferation is found between the vascular spaces. ${ }^{13}$ This tumor grows considerably during the period of three to six months of life, afterwards stabilising its size over several additional months; it finally begins to involute around two years of age, leaving as a sequel atrophic and wrinkled skin that deforms the anatomic structure on which it sits.

The major clinical problems posed by facial cavernous hemangiomas, apart from those derived from the esthetic monstrosities, are the total closure of one or both eyes that may lead to visual loss, occlusion of the external respiratory tract, feeding difficulties, and occasionally hemorrhage. Curiously more attention has been devoted to the angiographic findings in the territory of the external carotid artery, particularly with a view toward therapeutic embolization, than to those of the internal carotid distribution which in general are the more important.

In very circumscribed and well delineated hemangiomas with discrete localisation in the orbital, parotid, palatine, lingual, or maxillonasal zones, we have been able to appreciate, by angiography, the blood flow to the vascular anomaly across one or several branches of the external carotid. The vascular malformation appears as prominently in the arterial phases as in the capillary and venous phases. An abundance of vascularisation is manifest in all cases. When the angioma is situated in the orbital zone, vascular filling is derived from branches of the superficial anterior temporal artery. In the majority of cases some blood also is provided via the ophthalmic artery. While this vessel usually arises from the internal carotid and the anterior part of the carotid siphon, in some of these cases we also have seen the ophthalmic artery originate anomalously from a branch of the external carotid artery. In the cases of intraorbital angioma, vascularization from both sides may be verified. We have never seen these circumscribed angiomas associated with intracranial vascular malformations, however.

Another distinct feature is the giant cavernous hemangioma of the scalp and face, localised to one or both sides, that are associated with constitutional alterations in the territory of the internal carotid artery. We always observe the same change, an aneurysmal dilatation of the internal carotid artery from its origin to at least the zone of the carotid siphon, although in some cases the anomaly may extend to all the branches of the internal carotid from its origin to its end, constituting a true homolateral mega-arterial system always ipsilateral to the external angioma. When the facial vascular alteration was bilateral the intracranial vascular anomaly also involved both sides, although the more affected was always in the zone of the carotid siphon and of the circle of Willis. In this region when cavernous or capillary hemangioma is associated, some very anomalous vessels emerge, many of them not identifiable as corresponding to the persistence of any known embryonic connections in the early stage of vascular development.

Apart from having observed the cavernous hemangioma much more frequently in girls than in boys, the intracranial vascular alterations also have been much more severe in girls. although the characteristics of the facial and scalp hemangioma were similar to those of the male. There is no obvious reason to explain the differences between the sexes.

Nevus Flammeus - This is a capillary hemangioma consisting of mature congested capillaries in a subepidermal location. These vascular ectasias continue to increase in size with age. External warmth and crying increase their dark red colour. They are evident from birth, localised in the face, head, and other parts of the body. At times the nevus is accompanied by hypertrophy of the soft tissues and bone that may produce a somatic hemihypertrophy consituting the Klippel-Trenaunay syndrome. Its facial localisation can follow the dermatomes of one, two, or all three sensory branches of the fifth cranial nerve on one or both sides.

The fundamental condition constitutes the Sturge-Weber syndrome. The localization of all or part of the hemangioma is 

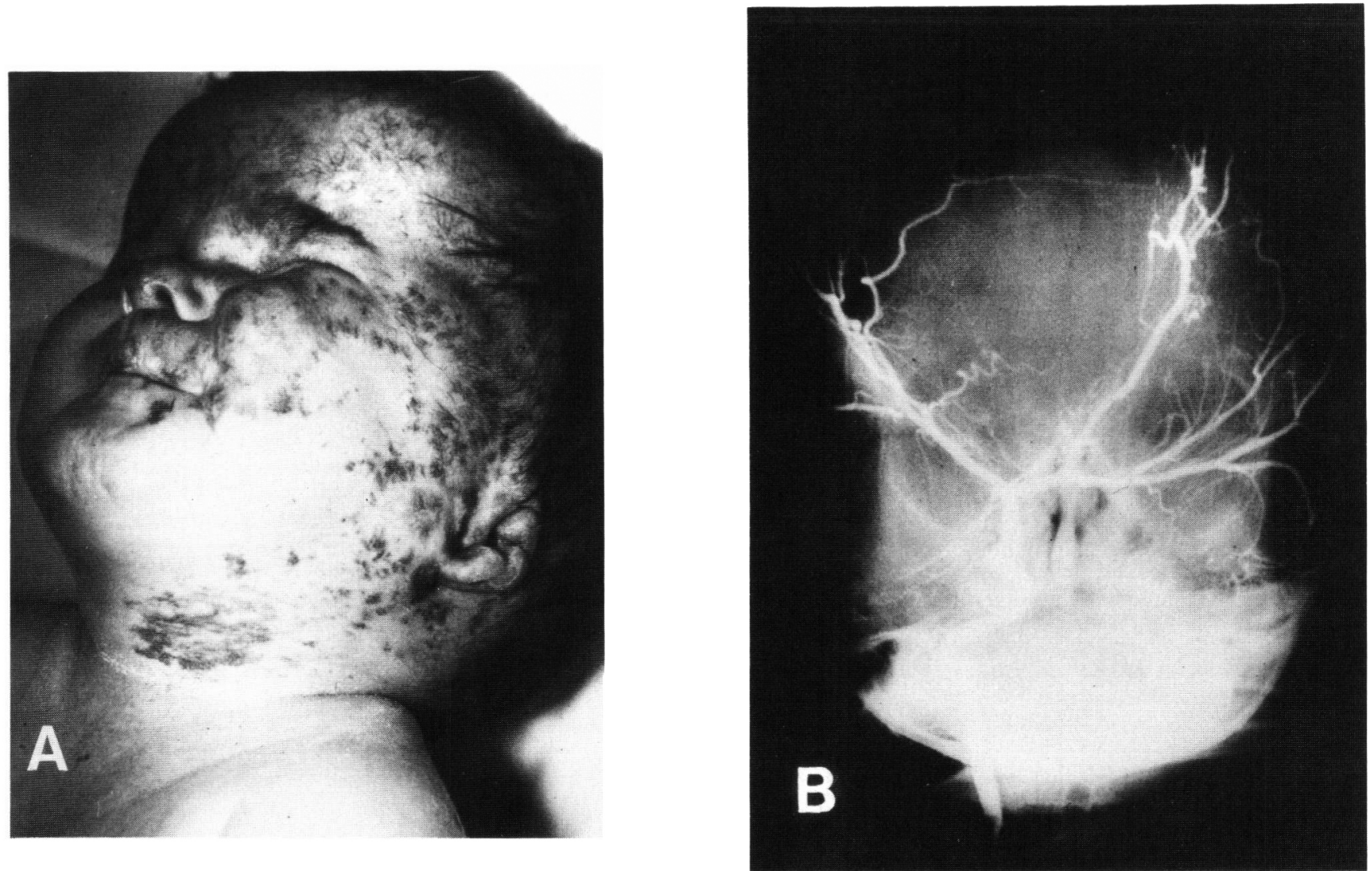

Figure 2 - Case 4. (A) 7-month-old girl with capillary hemangioma of left hemiface. The left ear exhibits an appearance corresponding to a 13 mm human embryo. (B) Right carotid arteriography shows vascularisation of both cerebral hemispheres arising from the division of this artery into three branches of distribution. The appearance and localisation are abnormal. their ramifications also being abnormal with an angiomatous appearance.

the zone corresponding to the first trigeminal branch. In these cases it customarily also shows cortical-subcortical calcifications in the ipsilateral cerebral hemisphere. Nevertheless, we have seen exceptional cases of Sturge-Weber syndrome with all the cerebral symptomatology unaccompanied by facial nevus flammeus. On the other hand, we never have been able to document objective neurologic and neuroradiologic alterations in cases in which the nevus flammeus of the face did not affect the territory of the first trigeminal branch.

Histologically there is no proliferation of endothelial cells, but loose collagenous tissues are seen in the ectatic vessels. Some authors believe that the nevus flammeus may represent a telangiectatic state of the capillaries owing to a congenital weakness of the wall, rather than being a true angioma. ${ }^{14.15}$ The radiologic findings ${ }^{16}$ and histologic findings ${ }^{17.19}$ seem to provide evidence of the progressive evolution of the cerebral calcifications and of their vascular origin, probably because of alterations in the permeability of vessel walls and stasis in the vascular lake that determine an anoxic lesion of the endothelium. ${ }^{20}$ These facts have been demonstrated by cerebral angiography in vivo. ${ }^{21}$

In the angiographic study carried out in 22 of the 38 patients of our series, we have been able to consistently demonstrate the presence of venous angiomas intracranially in only 5 cases. These consisted of one or several veins of enlarged and tortuous character that emptied normally in the venous sinuses, always in the hemisphere ipsilateral to the facial angioma. When the facial nevi were bilateral, the intracranial venous angioma also was bilateral, situated in the median or paramedian zone and emptying into the superior longitudinal sinus. We do not know if the percentage of venous anomalies found in our series is real or related to the young age of the majority of our patients. 80 percent of whom were less than 8 years of age. It is possible that the tendency to progression of this vascular anomaly may increase the mean percentage that increases with age of the subjects. Neither could we include the experiences of other authors because of the sparseness of large series in the medical literature. We never encountered an intracranial arterial or arteriovenous malformation or other type of arterial anomaly. and references to it in the literature are few. We are familiar only with the description of an infant boy of one year with SturgeWeber syndrome who presented with an aberrant artery originating from the posterolateral zone of the proximal portion of the cavernous segment of the internal carotid artery. ${ }^{22}$

A usual feature in the Sturge-Weber syndrome is the generalized hypoplasia of the carotid system in the atrophic hemisphere relative to that of the normal side. In spite of experience with repeated angiographic studies being sparse, (only two cases had carotid angiography repeated at several ages) it is our impression that hypoplasia of the intracranial arteries is more readily recognized with time, including progressive obstruction in some segments. Neither is the association of nevus flammeus usually described with other types of vascular malformations. Nevertheless, we have observed three cases with the evolution of a portion of nevus flammeus towards well circumscribed verrucous nodular hemangioma. One was localised in the upper 


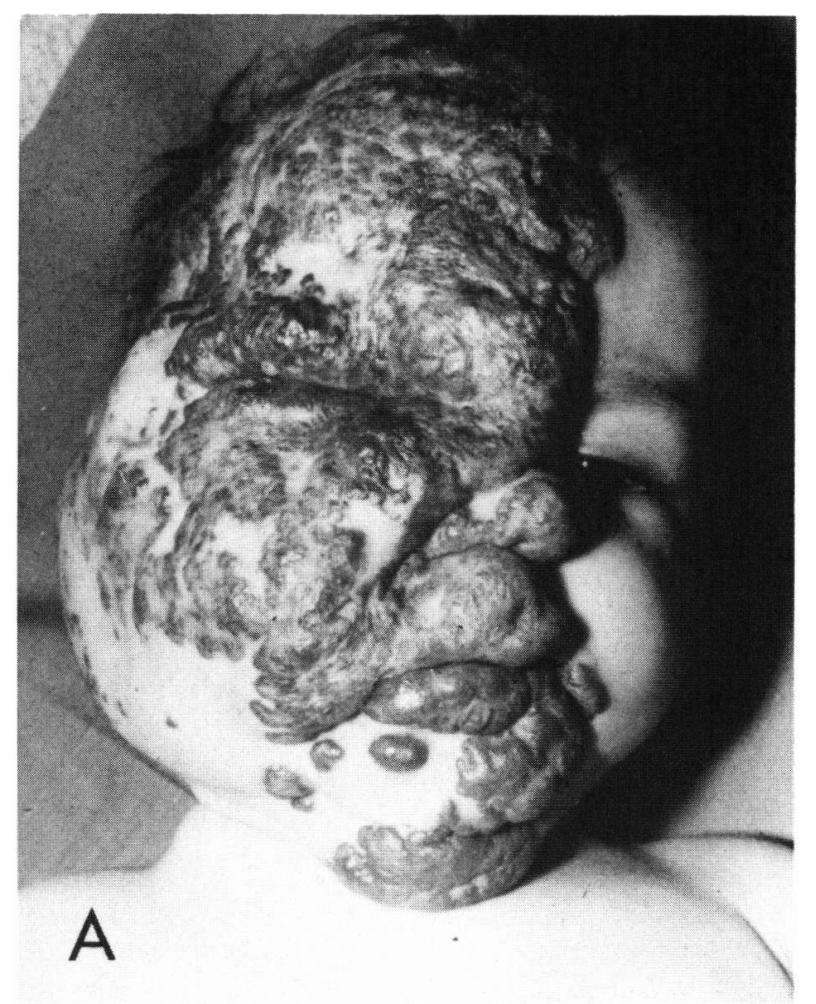

lip and showed no other alterations. Another was on the forehead and had a progressive growth over two years, between the ages of 12 and 14 years, finally reaching a great prominence even if momentarily totally reduced by digital pressure. Its principal clinical alteration was local pain caused by distension of the tissues, disappearing with pressure. This angioma filled by an enlarged branch with angiomatous appearance that arose from the anterior portion of the superficial temporal artery, or by another branch also quite enlarged, that originated in the palate and developed over several months in a 3-year-old girl. This palatine artery was filled by a thick branch that arose from the internal maxillary artery.

In children with Sturge-Weber syndrome whom we have followed since the neonatal period over several years we have documented an increase in the density and extent of the calcified zones as well as the appearance of cerebral cortical-subcortical atrophy that progresses with the passage of time, at least during the first years of life. This observation agrees with the findings of Norman and Schöne ${ }^{20}$.

Lymphangioma - This is a congenital malformation originating from dilated lymphatic canals possessing normal endothelium. The lymphatic vessels are derived from the same mesenchyme as that giving origin to the vascular system. Four types of lymphangiomas are known: simple, circumscribed, cystic, and diffuse. All are present since birth or appear in infancy.

Despite the lymphangioma being a developmental malformation, its association with intracranial arteriovenous malformations is extremely rare. The only two known cases are the one of Newton and Cronqvist ${ }^{23}$ who described an infant showing orbital lymphangioma and venous malformation with a small dural lake localized to the lateral sinus on the right, and our own case. ${ }^{24}$ In the latter, a 28 -day-old infant presented with a lymphangioma extending along the left side of the face and

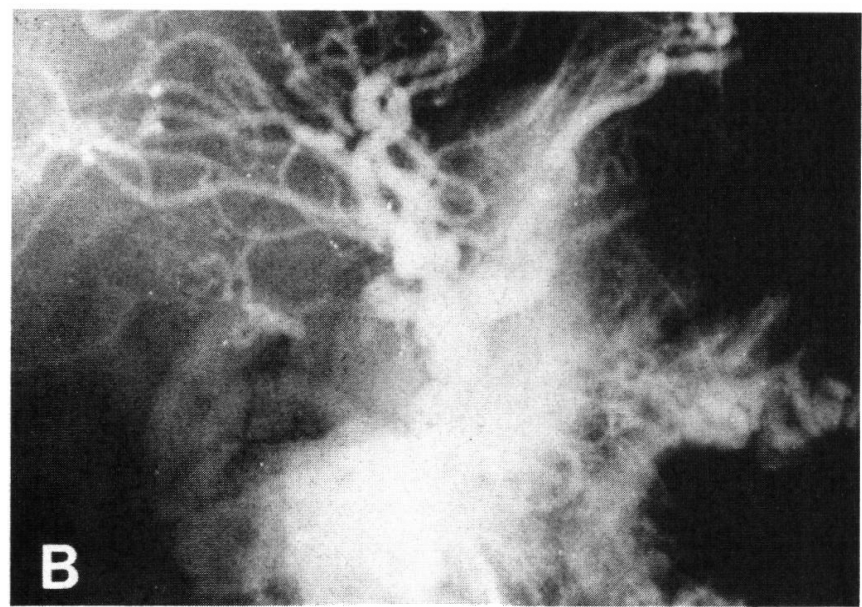

Figure 3 - Case 8(A) 12-month old girl with cavernous hemangioma of right hemiface which gives a monstrous appearance and partially involves the left side of the face as well. (B) Right carotid arteriography demonstrates an aneurysmal dilatation of the internal carotid artery and all its branches. Multiple angiomas also occur in the entire territory of the right external carotid artery.

scalp and completely occluding the eye (Fig. 4). In the CT-scan the irregular density of the extracranial lymphangioma was made evident, and a hyperdense zone that appeared totally opaque with contrast enhancement occupied the paramedian region and left side of the posterior cranial fossa. Cerebral angiography showed arteriovenous malformation with megaarteries in all principal branches of the two internal carotid arteries as well as the basilar artery and its terminal branches, so that all the blood converged into a gigantic aneurysmal dilatation of the left lateral sinus; the right lateral sinus also was pathologically engorged with blood. This child had severe psychomotor retardation. At about 2-1/2 years of age progressive deterioration was observed and he died at home at age $3-1 / 2$ years of unknown cause. Autopsy was not performed.

Despite the rarity with which the association of lymphangioma with intracranial arteriovenous malformation has been described, it seems logical that these two alterations should be related. Two contradictory theories attempt to explain the formation on the lymphatic system, a centrifugal and centripetal theory. The centrifugal theory is based on the studies of Sabin in 1902 from which he concluded that the jugular and posterior lymphatic sacs arose from neighbouring veins, while the lymphatic vessels were subsequently formed by outgrowths of the developing mesenchymal endothelium. ${ }^{25}$ Lewis in 1905 demonstrated that the lymphatic sacs separated from the veins in the embryologic stage of $16 \mathrm{~mm}$ to $20 \mathrm{~mm}$, but developed new connections with them toward the $30 \mathrm{~mm}$ stage. ${ }^{26}$ The centripetal theory is based on the studies of Huntington and McClure in 1910, who observed that lymphatic vessels do not form by proliferation of previously existing lymphatic sacs, but rather by the formation of mesenchymatous spaces that are subsequently transformed into a system of vessels that eventually become united with the venous system. ${ }^{27}$ Huntington maintained that the jugular sac and its 
zone of extension toward the outline of the extremities perforates the hematopoietic mesenchymatous tissue and contains primitive blood cell collections that are emptied into the venous circulation, after which the vessels revert to their own lymphatic system. ${ }^{28}$ Whichever theory more closely approaches the embryologic facts, it seems that the joint venous and lymphatic malformations in the head region are likely to take their origin as a disorder of mesenchyme during the 7 th to 9 th embryonic weeks.

\section{Embryologic development and vascular malformations of the brain}

\section{Ontogeny of the Cerebral Vasculature}

In placing these vascular anomalies into ontogenetic perspective it is necessary to make a chronologic summary of the embryonic development of the cerebral arteries, including both their origin at the aortic arch and their intracranial trajectories. The works of Mall, ${ }^{6}$ Streeter, ${ }^{12}$ Congdon, ${ }^{8}$ and Padget, ${ }^{9}$ constitute an obligatory wealth of consultation, and it is upon these early foundations that the following exposition is based.

The arteries that provide vascularization of the brain, namely the carotids and vertebrals, begin their development in the aortic arch. Two stages of this development are recognized: the primary or brachial stage appears at about 22 days and involves the appearance of a vascular apparatus destined to become the precursor of the posterior arteries; in the second or post-brachial stage the vascular apparatus mentioned is replaced by the adult arterial system during a period lasting about 28 days. The brachial stage begins with the formation of the first aortic arch and terminates somewhat arbitrarily with the interruption of the sixth arch. The sequence in the appearance of the different structures is: first aortic arch in the embryo of $1.5 \mathrm{~mm}$ ( 3 weeks) and the formation of angioblastic nests and preexisting capillaries; second aortic arch in the embryo of $3 \mathrm{~mm}(3-1 / 2$ weeks); third aortic arch in the embryo of $4 \mathrm{~mm}(3-1 / 2$ weeks); fourth aortic arch in the embryo of $4.6 \mathrm{~mm}$ (4 weeks); fifth aortic arch immediately after the sixth; sixth aortic arch in the embryo of 5 $\mathrm{mm}(4-1 / 2$ weeks). Each arch is formed from three elements, an outpouching from the aortic sac, a similar outpouching from the wall of the aorta and an intermediate endothelial capillary plexus in the corresponding visceral arch. The formative process is sequential, the first and the second arches disappearing with the formation of the third and fourth. The fifth appears after the sixth and is very transitory, disappearing almost as soon as it is formed. The fourth left arch takes part in the development of the aortic arch, the fourth right arch in that of the subclavian artery and the third arch of each side in the development of the common and internal carotid arteries.

There are disagreements with respect to the development of the external carotid arteries. Congdon concluded that they originate as an external growth from the aortic sac after the first and second aortic arches have disappeared. ${ }^{8}$ Their subsequent origin displaces the third aortic arch, becoming separated into a proximal part that forms the primitive carotid artery and a distal portion that gives origin to the proximal part of the internal carotid artery. Consequently, the common carotid arteries are formed after the involution of the wall of the aorta between the third and fourth arches in the embryo of $12 \mathrm{~mm}$ to $14 \mathrm{~mm} \mathrm{(35} \mathrm{to}$ 36 days). The internal carotid artery appears in the embryo of 3 $\mathrm{mm}$, and by $4 \mathrm{~mm}$ this vessel begins to present an anterior division, that is the outline of the future anterior cerebral, middle cerebral, and anterior choroidal arteries. The posterior division gives origin to the posterior communicating and posterior cerebral arteries in the embryo of $5.3 \mathrm{~mm}$; at this time the anterior cerebral artery is well defined and extends from the third aortic arch. The caudal division of the internal carotid artery has now formed a secondary anastomosis with the extreme cranial branch of the neuronal longitudinal artery in the mesencephalon, an embryonic vessel that will soon consitute the definitive posterior communicating artery and be totally substituted for the trigeminal artery.

When the embryo is in the third and last phase of the brachial stage, with a length of approximately 7 to $12 \mathrm{~mm}$ (32 to 35 days) the internal carotid artery already shows filling with blood in its intra-cerebral course, by contrast with its small trunk in the third aortic arch. The first important cerebral vessel in this location is the primitive dorsal ophthalmic artery. Subsequently the primitive anterior carotid artery appears and the first evidence of what will constitute the trunk of the middle cerebral arteries. In the transitional epochs of the brachial and postbrachial development, when the embryo is $12 \mathrm{~mm}$ to $14 \mathrm{~mm}$ (35 to 38 days), the common carotid artery may be identified and for the first time the cerebral ramification of the internal carotid artery and of its collateral vessels may be described as the earliest adult configuration.

The trigeminal artery begins to be seen in the embryo of $3 \mathrm{~mm}$ $(3-1 / 2$ weeks) as the second of the three vascular arms that are derived from the first aortic arch, passes dorsally arching next to the medial zone of the Gasserian ganglion. It consitutes the first source of blood supply to the posterior part of the primordial brain. When the embryo reaches $4 \mathrm{~mm}$ ( 28 days) the trigeminal artery communicates with fragments of the walls of the neural longitudinal arteries, of which the basilar artery forms completely when the embryo has reached $7 \mathrm{~mm}$ to $12 \mathrm{~mm}$ (4-1/2 to 5 weeks) by consolidation of the wall of the longitudinal neural arteries, although there are still discontinuous stretches. The formation of the basilar artery is accompanied by the involution of the trigeminal artery or its annexation by the internal carotid, becoming complete in the embryo of $14 \mathrm{~mm}$ ( 5 to $5-1 / 2$ weeks). Padget found embryos of $14 \mathrm{~mm}$ or somewhat longer in which the course of the trigeminal artery had not totally been interrupted. ${ }^{9}$ When the trigeminal artery presents after birth it constitutes an important vascular malformation anastomosing the internal carotid system with the basilar artery, a function normally substituted by the posterior communicating artery. The superior cerebellar arteries appear during the $7-10 \mathrm{~mm}$ stage (4-1/2 weeks), supplying part of the anterior zone formerly provided by the trigeminal artery.

The embryo of $9 \mathrm{~mm}$ to $11 \mathrm{~mm}$ (32 days) with a completely formed basilar artery is in an intermediate phase of anastomosis with the carotid system (still across the trigeminal arteries) and with the vertebral system. If vascular development is arrested or is occluded between 32 and 36 days, the basilar artery could exist without the vertebral artery having formed. The vertebral arteries begin to form when the embryo is $9 \mathrm{~mm}$ ( 32 days) by longitudinal anastomosis between superior longitudinal segmental arms of the dorsal aorta with subsequent obliteration of all aortic connections except those of the seventh cervical segmental arches, which remain as the subclavian trunk. By the time the embryo measures $12.5 \mathrm{~mm}$ (35 days) the vertebral arteries complete their formation but still originate from the wall of the aorta. The vertebral arteries finish their maturity when the embryo reaches $14 \mathrm{~mm}$ to $16 \mathrm{~mm}$ (between 36 and 40 days), with their origin having been displaced to the level of the ductus arteriosus. 

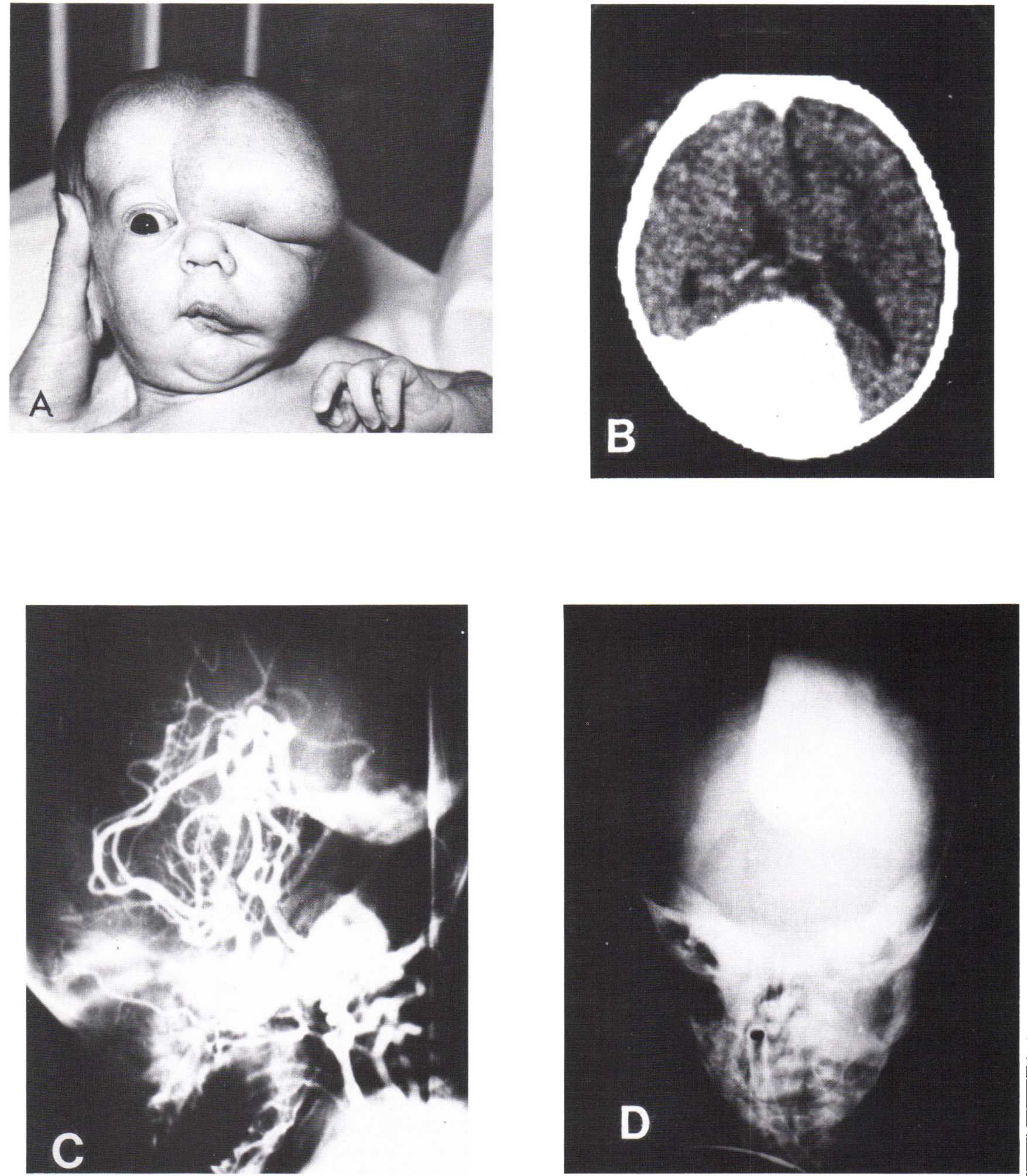

Figure 4-Case 9. (A) 4-month-old bov with lymphangioma in left hemifacial zone which totally occludes the left eve. (B) Computed tomography with contrast enhancement shows a greatly increased density in the entire left posterior quadrant, this zone corresponding to an aneurysmal left lateral sinus. The ventricular system is displaced by the vascular malformation. (C) Panarteriography demonstrates angiomatous dilatation of the basilar artery and of the posterior cerebral arteries as the left internal carotid and its branches are directed toward a great aneurysmal cavity situated in the posterior half of the cranial cavity. (D) The venous phase of the angiogram show's a giant aneurysmal dilatation of the left lateral sinus and a moderate dilatation of the right lateral sinus. 


\section{Developmental Aberrations in the Vasculature and Brain}

From our findings, we deduce that the embryo should be affected in the zone of development of the Gasserian ganglion in earlier periods when the teratogenic possibilities are pluripotential, although related to one another. The type of cutaneous vascular lesion depends on the state of embryonic development. The type of anomaly of intra- and extracranial vessels and concomitant cardiopathies may lead us to believe that the capillary hemangioma is related to an earlier noxious event than the lymphangioma. The association of facial capillary hemangiomas with alterations in the formation of the embryonic cerebral arteries of more precotious appearance is beyond doubt. For uncertain reasons there is a failure of formation of some definitive arteries that were intended to ascend to the cerebral hemisphere ipsilateral to that of the hemangioma, which obliges the arteries of first appearance to persist, including the development of contralateral connections and great embryologic complication as occurred in our case 3. This arrest of embryologic development not only affects mesoblastic structures (vessels and heart) but also the ectoblastic zones (cerebellum and ear) as happened with our case 4 , who presented a Dandy-Walker syndrome with involvement of the ear on the side of the hemangioma and development corresponding to an embryo of $13 \mathrm{~mm}$. The reason why hemangiomas are localized more often on the left side is not apparent.

Due to the persistent trigeminal artery it is much more common for embryonic anastomoses to be between the internal carotid and vertebral artery than are found postnatally and can be observed in different variations in three types of angiographic appearance: 1) the entire vertebral arterial system distal to the anomalous anastomosis was supplied through the anastomosis and the posterior communicating artery was very poorly filled; 2) the anastomosis primarily supplied the superior cerebellar arteries bilaterally, while the posterior cerebral arteries received their blood supply across their respective posterior communicating arteries, not always filling the most rostral portion of the basilar artery; 3 ) this third type is a combination of the first two; the ipsilateral posterior cerebral artery receives its blood supply via the posterior communicating artery while the anastomosis supplied the superior cerebellar arteries bilaterally and the contralateral posterior cerebral artery. ${ }^{29}$

The references in which persistence of the trigeminal artery are associated with an intracranial aneurysm with or without associated hemorrhage, trigeminal neuralgia, or other types of manifestations in the adult are so numerous they will not be detailed here. Among them are many published reports documenting an association between the persistent trigeminal artery with unilateral or bilateral hypoplasia of the vertebral artery, and absence of the posterior communicating artery with absence or hypoplasia of the proximal portion of the posterior cerebral artery. The origin of the two anterior cerebral arteries is from the same carotid artery in these cases and other anomalies occasionally may be found not directly related to the persistence of the trigeminal artery.

It had been thought that the direction of blood flow in cases of persistent trigeminal artery was from the carotid toward the basilar artery ${ }^{30}$ Nevertheless. Huber demonstrated that the arterial pressure is the same in the carotids as in the vertebrals and that the blood flow may course in either direction under various conditions. ${ }^{31}$ This hypothesis was soon confirmed. ${ }^{32-35}$ Padget, referring to the embryology of the primitive trigeminal artery, suggested the name "persistent trigeminal artery" for this carotid-basilar anastomosis because of its intimate relation with the Gasserian ganglion. ${ }^{9}$ and his assertion is confirmed by the findings observed in our patients, in which the persistence of the trigeminal artery is associated with capillary hemangioma in zones of the face and scalp innervated by the trigeminal nerve.

Mizuno et al presented a female child with characteristics similar to our cases in that she had left facial hemangioma associated with stenosis of the internal carotid artery, suprasiphonic aneurysm with abundant collateral circulation in this region, as well as hypoplasia of the left cerebellar hemisphere. ${ }^{36}$ The description of this patient associated with the 7 cases described by us seems to give consistency to an angiomatous syndrome that presents preferentially in girls and that involves facial hemangioma following a distribution in the territory of the sensory trigeminal nerve in one or two of the three branches. but always includes the first. Vascular alterations are diverse and major in the carotid and/or vertebral arteries. While generally intracranial, they also may occur extracranially and a significant percentage of cases involve a wide range of cerebellar malformations or hypoplasia.

The hypoplasia of the cerebellar hemisphere in our case 3 is ipsilateral to the side on which there also is absence of the vertebral and of the posterior inferior cerebellar (PICA) arteries. Bilateral cerebellar aplasia may be related to persistence of the hypoglossal artery, a more caudal vessel than the trigeminal in the series of transitory embryonic arteries. ${ }^{37}$ Certainly little attention has been paid to the pathogenesis of this neural anomaly even though it is well referenced in cases where the PICA was supplied across a persistent ipsilateral trigeminal artery without filling of the basilar artery. ${ }^{35.38 .39}$ Considering that the cerebellum begins its development considerably later than the vascular structures form, it would seem that these cerebellar anomalies may be fundamentally related to preceeding vascular alterations.

\section{CONCLUSIONS}

On the basis of our observations, we conclude the following: 1) The capillary angioma is related to anomalous origins of the cerebral arteries and persistance of some embryonic arteries that should have disappeared in the course of fetal development: 2) The cavernous hemangioma is associated with the angiomatous malformation of arteries which alsoexhibit aneurysmal dilatation along all or part of their course; 3 ) The nevus flammeus is associated with venous angioma; 4) The lymphangioma is associated with an arterial malformation similar to the cavernous hemangioma, and aneurysm of the lateral sinuses: 5) There is without doubt a topographic relation between the distribution of the cutaneous lesions and facial vascular prominences, with intracranial angiomatous alterations. The facial involvement in the territory innervated by the first branch of the trigeminal nerve seems determinant in its relation with other vascular alterations. The greater the extent of the capillary hemangioma of the face, the greater is the vascular anomaly encountered intracranially. 6) Cerebellar malformation also seems more severe when the degree of facial involvement by the capillary hemangioma is large. The more severe associated vascular alterations are more dependent upon alterations of PICA: 7) Congenital heart disease does not seem to be directly related to the severity of intracranial hemangiomas, but the association of 
capillary hemangioma and congenital cardiopathy is relatively frequent; 8) The vascular anomalies are always found ipsilateral to the hemangioma or facial nevus, underscoring the intimate relation between these alterations and the point in time of the pathology resulting from the same noxious influence; 9) The type of facial angiomatous alteration seems to be a determined vascular alteration fundamentally dependent on the embryologic period in which the noxious influence was active; 10) Mental retardation or limited intellectual level is observed in many subjects with angiomatous stains of the face and/or scalp, always when these dermal lesions are localised in facial dermatomes of the first trigeminal branch; 11) The state of patients with facial angiomas is not completely known if angiography is not carried out with visualization of all cerebral vessels from their origin in the carotid arch and course through the neck and into the intracranial cavity, and from the early arterial to the late venous phases.

\section{REFERENCES}

1. Margileth AM Developmental vascular abnormalities. Pediat $\mathrm{Cl} \mathrm{N}$ Amer 1971; 18: 773-800.

2. Lever WF, Schaumburg-Lever G Tumors of vascular tissue. In: Histopathology of the Skin. 6th ed. JB Lippincott. Philadelphia. 1983; pp 623-651.

3. Pascual-Castroviejo I, Roche Herrero MC, López-Terradas JM, et al Sindrome de Sturge-Weber. Hallazgos en 22 casos infantiles. An Esp Pediat 1978; 11: 281-294.

4. Pascual-Castroviejo I Vascular and nonvascular intracranial malformations associated with external capillary hemangiomas. Neuroradiology 1978; 16: 82-84.

5. Rathke, H Uber die Entwickelung der Arterien welche bei den Saugethieren von den Bogen der Aorta ausgehen. Arch $f$ Anat $1843 ; 270-302$.

6. Mall FP Determination of the age of embryos and fetuses. Manual of Human Embryology. V. 1, Keibel and Mall FP, (eds) Philadelphia 1912; pp 180-201.

7. Streeter GL The development alterations in the vascular system of the brain of human embryo. Contrib Embryol 1918; 8: 5-38.

8. Congdon ED Transformation of aortic arch system during the development of the human embryo. Contrib Embryol 1922; 14: 47-110.

9. Padget DH The development of the cranial arteries in the human embryo. Contrib Embryol 1948; 32: 205-262.

10. Rebollo M, Val JF, Garijo F, et al Livido reticularis and cerebrovascular lesions (Sneddon's syndrome). Clinical, radiological and pathalogical features in eight cases. Brain 1983; 106: 965-979.

11. Bussone G, Parati EA, Boiardi A, et al Divry-van Bogaert syndrome. Clinical and ultrastructural findings. Arch Neurol 1984;41:560-562.

12. Streeter GL Development of the auricle in the human embryo. Contrib Embryol 1922; 14: 111-118.

13. Wilkin JK Unilateral dermatomal cavernous hemangiomatosis. Dermatologica 1980; 161: 347-354.

14. Schnyder UW Zur Klinik und Histologie der Angiome. 4. Mitteilung Die planotuberösen Angiome des Kleinkindes. Arch Klin Exp Dermatol 1957; 204: 457-471

15. Barsky SH, Rosen S, Geer D, et al The nature and evolution of port wine stains. J Invest Dermatol 1980; 74: 154-157.
16. Pascual-Castroviejo I Sindrome de Sturge-Weber. In: Neurología Infantil. Ed Científico-Médica, Barcelona. 1983; pp 664-669.

17. Alexander GL, Norman RM The Sturge Weber syndrome. In: Bristol, Wright 1960; Chap. 5. pp 55-70.

18. Guseo A Ultrastructure of calcification in Sturge-Weber disease. Virchows Arch Path Anat 1975; 366: 352-356.

19. Di Trapani G, Di Rocco C, Abbamondi AL, et al Light microscopy and ultrastructural studies of Sturge-Weber disease. Child's Brain 1982; 9: 23-36.

20. Norman MG, Schöne WC The ultrastructure of Sturge-Weber disease. Acta Neuropathol 1977; 37:199-205.

21. Bentson JR, Wilson GH, Newton TH Cerebral venous drainage pattern of the Sturge-Weber syndrome. Radiology 1971; 101: 111-118.

22. Ito J, Takeda N, Suzuki Y, et al Anomalous origin of the anterior inferior cerebellar arteries from the internal carotid artery. Neuroradiology 1980; 19: 105-109.

23. Newton TH, Cronqvist S, Involvement of dural arteries in intracranial arteriovenous malformations. Radiology 1969: 93: 1071-1078.

24. Scavone C, Pascual-Castroviejo I, Tendero A, et al Malformación ateriovenosa intracraneal gigante (MAVG) y linfangioma facial. An Esp Pediat 1980; 13: 589-592.

25. Sabin FR On the origin of the lymphatic system from the veins, and the development of the lymph hearts and thoracic duct in the pig. Amer J Anat 1902; 1: 367-389.

26. Lewis FT The development of the lymphatic system in rabbits Amer J Anat 1905: 5: 95-111.

27. Huntington GS, McClure CFW The anatomy and development of the jugular lymph sac in the domestic cat. Amer J Anat 1910; 10: 177-311.

28. Huntington GS The development of the mammalian jugular lymph sac, of the tributary primitive lymphatic and of the thoracic ducts from the viewpoint of recent investigations of vertebrate lymphatic ontogeny together with a consideration of the genetic relations of the lymphatic and haemal vascular channels in the embryos of amniotes. Amer J Anat 1914; 16: 259-316.

29. Saltzman G Patent primitive trigeminal artery studies by cerebral angiography Acta Radiol 1959; 51: 329-336.

30. Tönnis $W$, Shiefer $W$ Zirkulationsstörungen des Gehirns im Serienangiogramm. Springer. Berlin 1959.

31. Huber P Die a.trigemina primitiva. Betrachtungen zur Klinischen Bedeutung der carotidobasilaren Anastomosa. Deutsch Z Ner. venheilk 1961; 181: 612-633.

32. Nadjmi $M$ Über die Arteria primitive trigemina im carotid und Vertebralisangiogramm. Deutsch Z. Nervenheilk 1961; 182: 231-237.

33. Neilsen PB, Jonson M Persistent primitive trigeminal artery demonstrated by vertebral arteriography. Amer J Roentgenol 1967; 101: 47-51.

34. Szdzuy D, Lehman R Persistent trigeminal artery in vertebral angiography. Neuroradiology 1971:2: 100-101.

35. Teal JS, Rumbaugh CL, Bergeron RT, et al Persistent carotidsuperior cerebellar artery anastomosis: A variant of persistent trigeminal artery. Radiology 1972: 103: 335-341.

36. Mizuno $Y$, Kurokawa $T$, Numaguchi $Y$, et al Facial hemangioma with cerebrovascular anomalies and cerebellar hypoplasia. Brain Develop 1982; 4: 375-378.

37. Pascual-Castroviejo 1, Tendero A, Martínez-Bermejo A, et al Persistence of the hypoglossal artery and partial agenesis of the cerebellum. Neuropädiatrie 1975; 6: 184-189.

38. Newton TH, Potts DG Radiology of the Skull and Brain. V. 2. CV Mosby. St. Louis. 1975; pp 1710-1795. 